\title{
Family Resemblances
}

\section{Justin Hayes, Paul Pasquaretta, and Glenda Pritchett} Quinnipiac University

Of some concern in higher education is the instability of meaning associated with critical thinking. Its definitions have become either incompatible with one another (e.g., Johnson \& Hamby, 2015) or "so broad that it can encompass nearly anything and everything" (Schmaltz, Jansen, \& Wenckowski, 2017, p. 1). Given the importance of critical thinking, as attested by regular inclusion of the term in university mission statements, teacher association rubrics, and pedagogical journals, its incompatibility and underdetermination of meaning seem to pose a significant challenge to the development of learning outcomes:

If we cannot agree on what critical thinking is, it is difficult to see how we can agree on the kinds of skills a person should have who regularly achieves the ends of critical thinking, whatever those ends happen to be. (Johnson \& Hamby, 2015, p. 420)

While there have been notable efforts to form a consensus on the meaning of critical thinking, the results, such as the landmark Delphi Report (Facione, 1990), have always been undone by the emergence of alternative definitions. Indeed, this volume of Double Helix, in which the following definitions of critical thinking are presented, may be seen as the latest unraveling of any such agreement:

- transference of skills and knowledge when encountering new situations

- the ability to use higher order cognitive skills such as synthesis and evaluation

- a set of skills and mental processes for problem-solving

- a way of formulating or critiquing arguments

- a discipline-specific practice

- a general intellectual approach or attitude

- a process involving the development of the following skills: observation, reasoning, decision-making, analysis, judgment and persuasion, along with categorizing, selecting, differentiating, comparing and contrasting

- an active construction of conceptual relations between new and existing knowledge

- the replication of instances of successful thinking in learning settings

- a metacognitive process through which students become able to determine what they need to know and how they can learn it by engaging in reflection

- an informed look at something. . . examining available information and drawing intelligent conclusions through analyzing and synthesizing, preferably from a relatively disinterested point of view 
Is critical thinking an attitude or a process or a skill or a practice? Is it cognitive or metacognitive? Is it a transference of knowledge or a construction of its conceptual relations?

This problem of consensus presupposes that there should be a single definition of critical thinking. Moore (2013), however, contested this supposition by invoking Wittgenstein's observation that a word acquires its meaning not by abstraction but by its actual use. The various definitions attached to critical thinking reflect, then, the ways it is exercised in particular contexts. Moore suggested that these definitions can nevertheless be related through Wittgenstein's notion of family resemblances. Wittgenstein (1973) described family resemblances as "a complicated network of similarities overlapping and criss-crossing" ( $\S$ 66). If critical thinking denotes a network of definitions, then incompatibility and underdetermination can be seen instead as its open-endedness of meaning. Consider, for example, a crisscrossing of similarities in which definiens HGECB intersects with definiens DGI at element G and with definiens ACF at element C:

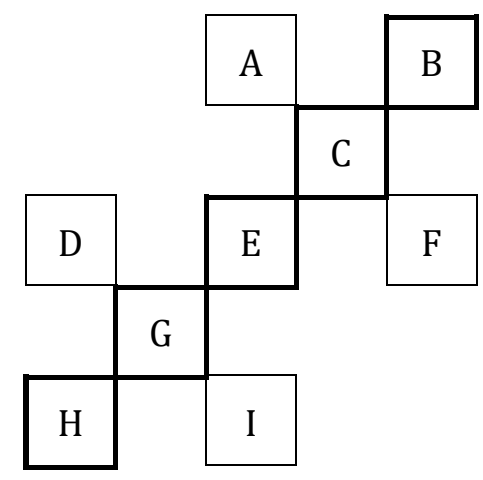

Elements D, I, A, and F are dissimilar to HGECB and therefore represent underdetermination. Now, consider DGI to be incompatible with definiens KLM, yet each overlaps with definiens IJK:

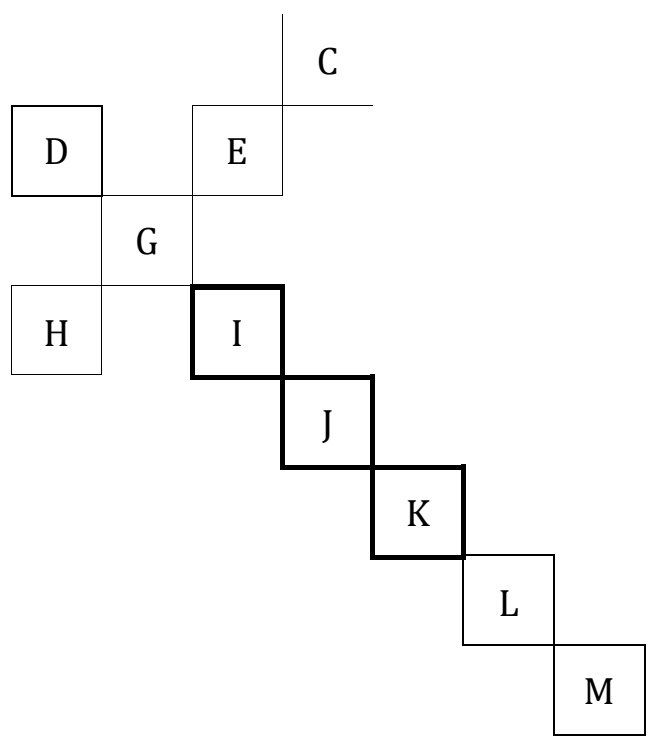


Through this overlapping of similarities, D and I as well as KLM are assimilated into the network as new variations of meaning. And as dissimilarities among other definientia are discovered to overlap and intersect with the existing network, additional connections are made, producing further variations. And so, when critical thinking is reconsidered within this genetic organization of meaning, incompatibility and underdetermination, which otherwise interfere with the formation of consensus, are instead part of the evolving nature of critical thinking, around which consensus can form as changing and interrelated areas of agreement about what students need to learn.

The term critical thinking may, then, be less a cause for concern than an occasion to imagine new possibilities. What family resemblances can be traced among the definitions presented in this volume and beyond? Might the particular contexts of writing within which critical thinking operates be networked to generate new lines of writing across the curriculum? What learning outcomes would follow? We invite readers to take up these questions as they explore this and other volumes of Double Helix.

\section{References}

Facione, P. A. (1990). Critical thinking: A statement of expert consensus for purposes of educational assessment and instruction. Research findings and recommendations. Newark, DE: American Philosophical Association.

Johnson, R. H., \& Hamby, B. (2015). A meta-level approach to the problem of defining "critical thinking." Argumentation, 29(4), 417-430.

Moore, T. (2013). Critical thinking: Seven definitions in search of a concept. Studies in Higher Education, 38(4), 506-522.

Schmaltz, R. M., Jansen, E., \& Wenckowski, N. (2017). Redefining critical thinking: Teaching students to think like scientists. Frontiers in Psychology, 8, 1-4.

Wittgenstein, L. (1973). Philosophical investigations ( $3^{\text {rd }}$ ed.). (G. E. M. Anscombe, Trans.). New York, NY: Macmillan. 